\title{
ANALISA PATH LOSS SPEKTRUM FREKUENSI UHF UNTUK PENYIARAN TV TERESTRIAL KOTA PADANG
}

\author{
Hanalde Andre ${ }^{1 *}$, Nofriadi ${ }^{2}$ \\ ${ }^{1}$ Jurusan Teknik Elektro, Fakultas Teknik, Universitas Andalas \\ ${ }^{2}$ Loka Monitor Spekfrekrad dan Orsat, Padang \\ *Corresponding author, e-mail: hanalde.andre@ @ft.unand.ac.id
}

\begin{abstract}
Abstrak-Perhitungan path loss sangat dibutuhkan dalam perencanaan maupun evaluasi layanan telekomunikasi. Penyiaran Televisi (TV) terestrial menggunakan spectrum frekuensi Ultra High Frequency (UHF) dalam rentang $478 \mathrm{MHz}-806 \mathrm{Mhz}$. Penelitian ini membahas penyiaran TV terestrial Kota Padang yang terdiri dari 14 pemancar. Perhitungan path loss dilakukan dalam area layanan kota Padang dengan menggunakan metode rekomendasi ITU-R P.525 dan rekomendasi ITU-R P.1546. Berdasarkan hasil perhitungan didapatkan hasil selisih rata-rata kedua metode tersebut sebesar $4.53 \mathrm{db}$.
\end{abstract}

Kata Kunci : Path Loss, TV terestrial, UHF, Kota Padang

\begin{abstract}
The calculation of path loss is needed in planning and evaluation of telecommunication services. Broadcasting Television (TV) terrestrial uses Ultra High Frequency (UHF) spectrum in the range of $478 \mathrm{MHz}-806 \mathrm{MHz}$. This study discuss the Padang city terrestrial TV broadcasting which consists of 14 transmitters. Path loss calculations is carried out in the Padang city service area using the ITU-R P.525 and ITU-R P.1546. Calculation results shows an average difference of the two methods is $4.53 \mathrm{db}$.
\end{abstract}

Keywords : Path Loss, Terestrial TV, UHF, Padang City

Copyright $(2017$ JNTE. All rights reserved

\section{PENDAhUluan}

Siaran Televisi (TV) merupakan salah satu media telekomunikasi satu arah (broadcasting) yang memberikan informasi berupa gambar bergerak (video) dan suara (audio). Penyiaran TV menggunakan teknologi terestrial dan satelit. Perbedaan kedua teknologi ini adalah pemancar yang digunakan. TV satelit menggunakan media satelit untuk memancarkan siarannya sedangkan TV terestrial menggunakan pemancar yang berada di bumi. Istilah terestrial ini umumnya digunakan di eropa sedangkan di amerika menggunakan istilah over-the-air (OTA).

Regulasi mengenai penggunaan spektrum frekuensi untuk penyiaran TV terestrial di Indonesia diatur oleh negara. Pemerintah banyak mengadopsi aturan maupun rekomendasi dari International Telecommunication Union (ITU). Institusi ini merupakan salah satu badan khusus PBB yang mewadahi bidang telekomunikasi. Indonesia merupakan salah satu negara yang menjadi anggota ITU.

Penyiaran TV terestrial menggunakan spektrum frekuensi Ultra High Frequency (UHF) dalam rentang $478 \mathrm{MHz}-806 \mathrm{MHz}$. Propagasi gelombang dalam spektrum tersebut memiliki redaman yang berhubungan dengan jarak propagasinya. Besarnya redaman tersebut menjadi hal yang menarik bagi para peneliti dan akademisi. Beberapa penelitian menggunakan rekomndasi ITU-R P.1546 untuk memprediksi besarnya redaman tersebut [1-4]. Selain rekomendasi tersebut beberapa metode juga digunakan sebagai pembanding [5-7].

Perhitungan redaman yang terjadi pada jalur propagasi penyiaran dalam telekomunikasi disebut dengan path loss. Nilai path loss tersebut mempengaruhi sinyal atau kuat medan yang diterima dalam suatu daerah layanan. Informasi mengenai kuat medan ini dapat dilakukan pada semua spektrum frekuensi, tidak hanya terbatas pada spektrum UHF [8]. Informasi mengenai path loss tersebut sangat bermanfaat untuk evaluasi maupun perencanaan layanan siaran di suatu daerah.

Penelitian ini membahas mengenai path loss yang terjadi pada spectrum frekuensi UHF untuk penyiaran TV terestrial Kota Padang. Terdapat 14 pemancar TV terestrial di kota Padang. Perhitungan dilakukan dengan menggunakan rekomendasi ITU-R P.525-2 dan rekomendasi ITU-R P.1546-5. 


\section{TINJAUAN PUSTAKA}

\subsection{Spektrum UHF}

Spektrum UHF terletak pada nomor pita 9 dengan rentang frekuensi $300-3000 \mathrm{MHz}$ seperti yang dapat dilihat pada Tabel 1. pada spektrum tersebut digunakan untuk radio astronomi, radio navigasi penerbangan, radio navigasi satelit, meteorologi, penyiaran televisi terestrial, radio lokasi.

Tabel 1. Klasifikasi Spektrum Frekuensi (ITU)

\begin{tabular}{|c|l|c|}
\hline No. Pita & Simbol & Rentang Frekuensi \\
\hline 4 & VLF & $3 \mathrm{~s} / \mathrm{d} 30 \mathrm{KHz}$ \\
\hline 5 & LF & $30 \mathrm{~s} / \mathrm{d} 300 \mathrm{KHz}$ \\
\hline 6 & MF & $300 \mathrm{~s} / \mathrm{d} 3000 \mathrm{KHz}$ \\
\hline 7 & HF & $3 \mathrm{~s} / \mathrm{d} 30 \mathrm{MHz}$ \\
\hline 8 & VHF & $30-300 \mathrm{MHz}$ \\
\hline 9 & UHF & $300-3000 \mathrm{MHz}$ \\
\hline 10 & SHF & $3-30 \mathrm{GHz}$ \\
\hline 11 & EHF & $30-300 \mathrm{GHz}$ \\
\hline
\end{tabular}

\subsection{PATH LOSS}

Propagasi gelombang elektromagnetik melalui udara mengalami redaman yang sebanding dengan jarak yang ditempuhnya. Path loss merupakan istilah yang digunakan untuk redaman tersebut.

\subsubsection{Model ITU-R P.525-2}

Model propagasi yang digunakan sesuai dengan rekomendasi ITU-R P.525-2. Model ini merupakan propagasi gelombang elektromagnetik tanpa halangan (free space). Metode ini telah banyak menjadi referensi dalam perhitungan untuk memprediksi path loss dari propagasi gelombang elektromagnetik [9].

$L_{f}=32.44+20 * \log (f)+20 * \log (d)$

Perhitungan rugi-rugi propagasi atau path loss dapat dilihat pada persamaan 1, dimana $L_{f}=$ Total path loss

$f \quad=$ Frekuensi saluran

$d=$ Jarak antar pemancar dan penerima

\subsubsection{Model ITU-R P.1546-5}

Salah satu rekomendasi ITU mengenai layanan telekomunikasi erestrial adalah ITU-R
P.1546-5. Rekomendasi ini adalah metode untuk memprediksi propagasi transmisi telekomunikasi dalam rentang frekuensi $30 \mathrm{MHz}$ hingga $3000 \mathrm{MHz}$ [10].

$$
E_{f s}=106.9-20 * \log (d)
$$

Dimana $E_{f s}$ adalah kuat medan maksimum $(\mathrm{dbuV} / \mathrm{m})$ dan $\mathrm{d}$ adalah jarak $(\mathrm{km})$. Berdasarkan rekomendasi ini didapatkan kuat medan maksimum tanpa penghalang yang diterima dapat dilihat pada persamaan (2). Perhitungan tersebut digunakan untuk daya radiasi efektif atau Effective Radiated Power (ERP) suatu pemancar sebesar $1 \mathrm{~kW}$. Hubungan antara ERP dapat dilihat pada persamaan 3 .

$$
L_{f}=E R P-E_{f s}
$$

Untuk nilai ERP $1 \mathrm{~kW}$ dengan impedansi saluran $75 \mathrm{ohm}$ didapatkan kuat medan sebesar $168.751 \mathrm{dbuV} / \mathrm{m}$, sehingga dengan mensubtitusi persamaan (3) dengan persamaan (2) didapatkan nilai path loss seperti pada persamaan (4).

$$
L_{f}=61.851+20 * \log (d)
$$

Perhitungan dengan menggunakan model ITU-R P.1546-5 menggunakan interpolasi dari nilai yang telah ditetapkan. Parameter yang diperhitungkan dalam model ini adalah,

\section{Frekuensi}

Nilai frekuensi yang terdapat pada grafik adalah $100 \mathrm{MHz}, 600 \mathrm{MHz}$ dan $2000 \mathrm{MHz}$. Untuk frekuensi lain menggunakan interpolasi dan ekstrapolasi dari nilai yang ditentukan, dengan menggunakan persamaan. Perhitungan dilakukan dengan menggunakan persamaan (5).

$\mathrm{E}=\mathrm{E}_{\text {inf }}+\left(\mathrm{E}_{\text {sup }}-\mathrm{E}_{\text {inf }}\right) * \log \left(\mathrm{f} / \mathrm{f}_{\text {inf }}\right) / \log \left(\mathrm{f}_{\text {sup }} / \mathrm{f}_{\text {inf }}\right)$

dimana,

$\mathrm{E}=$ Kuat medan yang diterima

$\mathrm{E}_{\text {inf }}=$ Kuat medan frekuensi bawah

$\mathrm{E}_{\text {sup }}=$ Kuat medan frekuensi atas

$\mathrm{f} \quad=$ Frekuensi yang dihitung

$\mathrm{f}_{\text {inf }}=$ Frekuensi bawah

$\mathrm{f}_{\text {sup }}=$ Frekuensi atas 


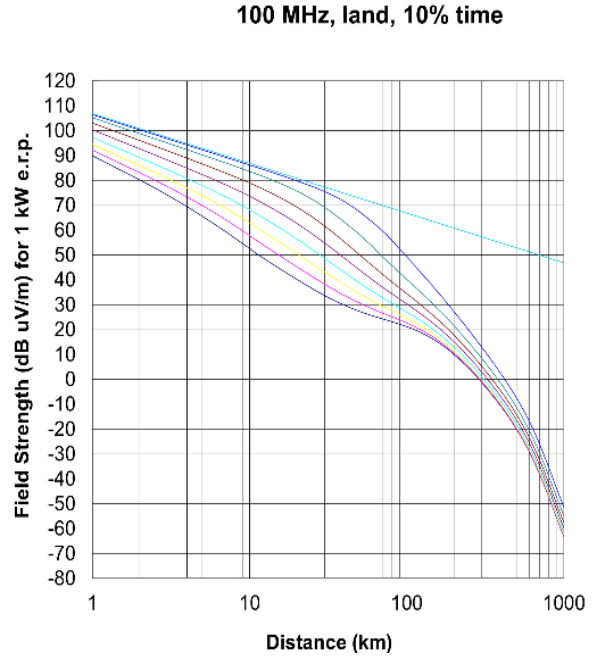

(a)

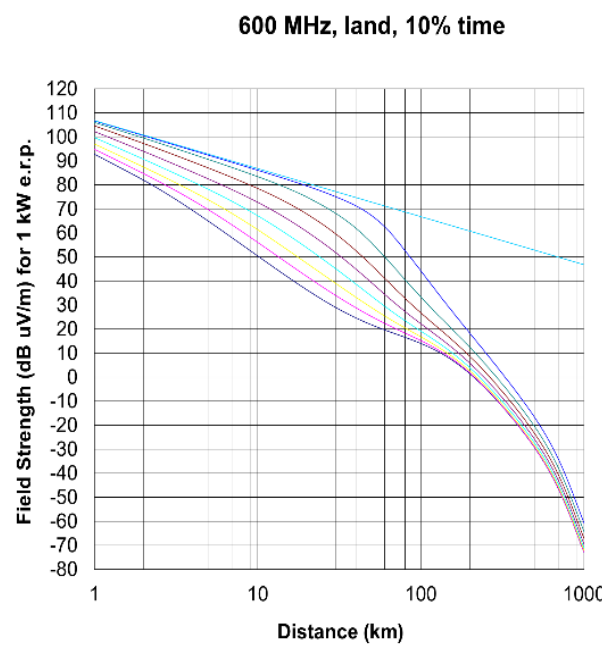

(b)

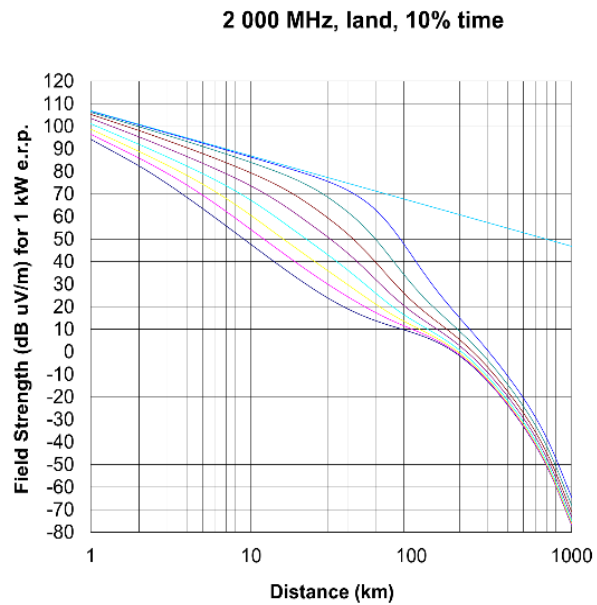

(c)

Gambar 1. Prediksi Kuat Medan Pemancar Berdasarkan ITU-R P.1546-5 (a) $100 \mathrm{MHz}$, (b) $600 \mathrm{MHz}$, (c) 2000 $\mathrm{MHz}$
Interpolasi dan ektrapolasi yang dilakukan berdasarkaan hasil perhitungan yang telah dilakukan ITU dapat dilihat pada Gambar 1. Perbedaan metode ini dengan ITU-R P.525-2 adalah memperhitungkan tinggi dari antenna pemancar. Nilai yang menjadi standar dalam perhitungan untuk frekuensi adalah $100 \mathrm{MHz}$, $600 \mathrm{MHz}, 2000 \mathrm{MHZ}$. Untuk ketinggian pemancar antenna menggunakan nilai $10 \mathrm{~m}, 20$ m, 37.5 m, 75 m, 150 m, 300 m, 600 m, dan 1200 $\mathrm{m}$.

\section{Tinggi antena pemancar}

Tinggi antena pemancar diperhitungakn dengan nilai $10 \mathrm{~m}, 20 \mathrm{~m}, 37.5 \mathrm{~m}, 75 \mathrm{~m}, 150 \mathrm{~m}$, $300 \mathrm{~m}, 600 \mathrm{~m}, 1200 \mathrm{~m}$ dan di atas $1200 \mathrm{~m}$. Interpolasi dan ekstrapolasinya menggunakan persamaan (6)

$\mathrm{E}=\mathrm{E}_{\text {inf }}+\left(\mathrm{E}_{\text {sup }}-\mathrm{E}_{\text {inf }}\right) * \log \left(\mathrm{h}_{1} / \mathrm{h}_{\text {inf }}\right) / \log \left(\mathrm{h}_{\text {sup }} / \mathrm{h}_{\text {inf }}\right)$

dimana,

$\mathrm{E}=$ Kuat medan yang diterima

$\mathrm{E}_{\text {inf }}=$ Kuat medan tinggi antena pemancar bawah

$\mathrm{E}_{\text {sup }}=$ Kuat medan tinggi antena pemancar atas

$\mathrm{h}_{1} \quad=$ Tinggi antena pemancar yang dihitung

$\mathrm{h}_{\text {inf }}=$ Tinggi antena pemancar bawah

$\mathrm{h}_{\text {sup }}=$ Tinggi antena pemancar atas

Interpolasi dan ekstrapolasi dilakukan terhadap parameter frekuensi dan ketinggian antena pemancar seperti yang dapat dilihat pada persamaan 6. Interpolasi dilakukan untuk parameter pertama, parameter selanjutnya dengan menggunakan ektrapolasi dari data yang didapatkan pada parameter pertama. sesuai rekomendasi ITU-R P.1546 parameter pertama adalah frekuensi yang diinterpolasi dan selanjutnya ketinggian pemancar antenna.

\section{METODOLOGI}

Perhitungan path loss spektrum frekuensi UHF untuk penyiaran TV terestrial Kota Padang menggunakan metode ITU-R P.525-2 dan ITUR P.1546-5. Jangkauan propagasi yang dibutuhkan untuk area layaanan kota padang sepanjang $20 \mathrm{~km}$. Pada Gambar 2 dapat dilihat panjang kota padang yang diukur menggunakan google maps. 


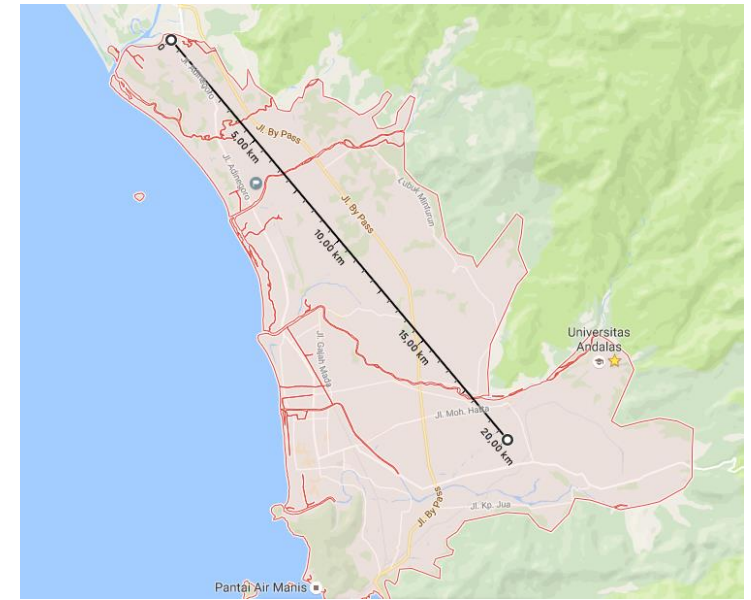

Gambar 2. Kota padang

Kota padang memiliki 14 pemancar TV terestrial yang beroperasi pada spektrum UHF. Pemancar tersebut berlokasi di bagian selatan kota padang pada kecamatan padang selatan, kecamatan pauh dan kecamatan lubuk kilangan. Salah satu pemancar TV terestrial kota padang dapat dilihat pada Gambar 3.

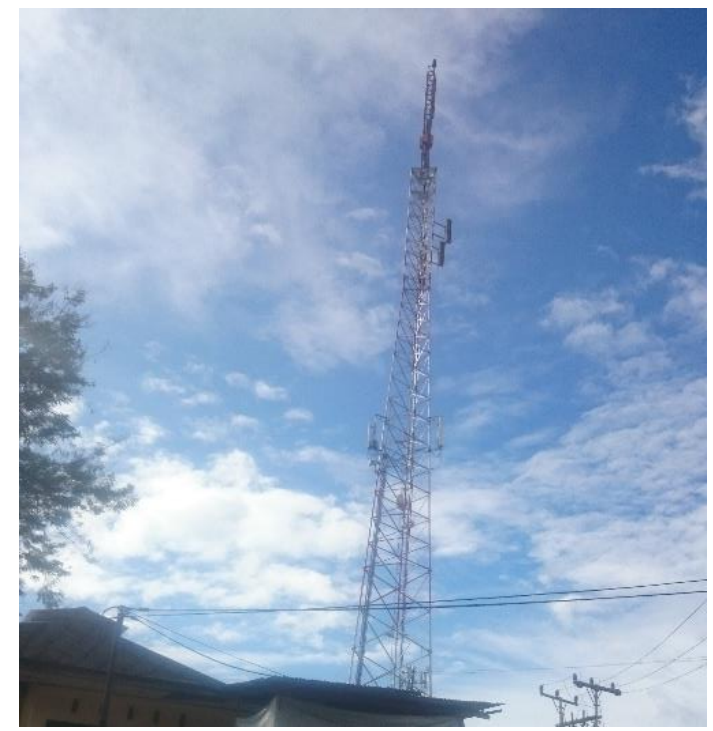

Gambar 3. Pemancar Stasiun TV Terestrial Kota padang (RCTI)

Daya efektif pemancar atau ERP dan tinggi antena pemancar TV terestrial kota padang dapat dilihat pada tabel 2. Daya efektif didapatkan dengan memperhitungkan gain antenna dan rugi-rugi transmisi. Satuan yang digunakan dalam daya efektif adalah dbm, dimana $60 \mathrm{dbm}$ setara dengan 1000 watt.
Tabel 2. Pemancar TV terestrial Kota Padang

\begin{tabular}{|c|l|c|c|}
\hline No. & Pemancar & $\begin{array}{c}\text { ERP } \\
(\mathbf{d b m})\end{array}$ & $\begin{array}{c}\text { Tinggi Antenna } \\
(\mathbf{m})\end{array}$ \\
\hline 1 & TRANS 7 & 67,85 & 55 \\
\hline 2 & TVRI & 71,373 & 40 \\
\hline 3 & TV ONE & 72,861 & 60 \\
\hline 4 & TRANS TV & 67 & 60 \\
\hline 5 & I NEWS & 73,31 & 65 \\
\hline 6 & KOMPAS TV & 75,931 & 45 \\
\hline 7 & NET & 70,052 & 40 \\
\hline 8 & GLOBAL TV & 69 & 45 \\
\hline 9 & MNC TV & 68 & 65 \\
\hline 10 & METRO TV & 73,161 & 68 \\
\hline 11 & RCTI & 77,3 & 45 \\
\hline 12 & ANTV & 69,761 & 100 \\
\hline 13 & SCTV & 73 & 100 \\
\hline 14 & INDOSIAR & 63,3 & 70 \\
\hline
\end{tabular}

\section{HASIL DAN PEMBAHASAN}

\subsection{Hasil Perhitungan Path Loss dengan metoda ITU-R P.525-2}

Pada Gambar 4 dapat dilihat hasil perhitungan path loss dengan menggunakan metode ITU-R P.525-5. Perhitungan dilakukan terhadap pemancar TV terestrial di kota padang dengan jarak $20 \mathrm{~km}$. Berdasarkan perhitungan dapat dilihat kenaikan nilai path loss seanding dengan besar frekuensi yang digunakan.

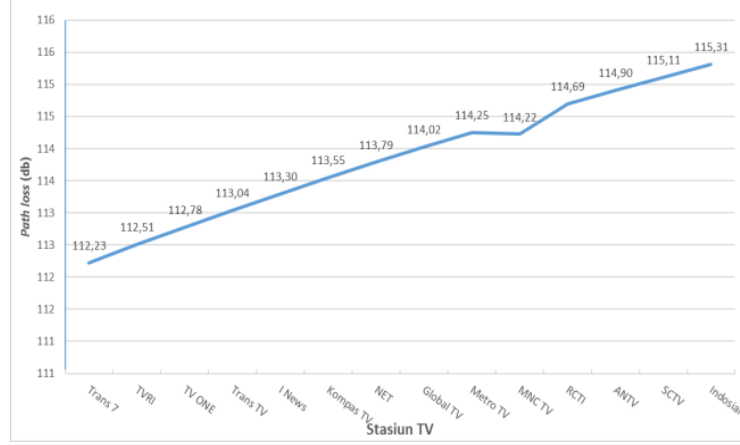

Gambar 4. Hasil Perhitungan Path Loss ITU-R P.525-2 pada jarak $20 \mathrm{~km}$

Kuat medan suatu pemancar berhubungan dengan path loss yang dilaluinya. Perhitungan dilakukan terhadap kuat medan pemancar TV terestrial kota padang pada jarak $20 \mathrm{~km}$ seperti yang dpat dilihat pada Gambar 5. Perbedaan kuat medan yang dihasilkan pemancar berhubungan dengan ERP pemancar tersebut. 


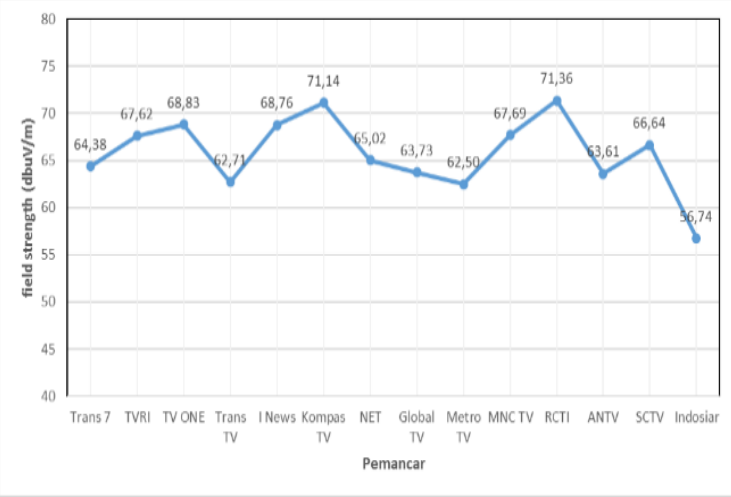

Gambar 5. Kuat Medan Pemancar dengan Metode ITU-R P.525-2 pada Jarak $20 \mathrm{~km}$.

Kuat medan yang dihasilkan pemancar TV kota padang sedikit berbeda dengan perhitungan path loss. Hal ini dapat disebabkan karena perbedaan ERP dari tiap-tiap pemancar. Kuat medan terbesar dihasilkan oleh pemancar RCTI sebesar $71.36 \mathrm{dbuV} / \mathrm{m}$ yang beroperasi pada frekuensi $647.25 \mathrm{MHz}$ sedangkan nilai pah loss terkecil dihasilkan oleh pemancar Trans 7 $112.23 \mathrm{db}$ pada frekuensi 487.25 MHz.

\subsection{Hasil Perhitunga Path Loss dengan metoda ITU-R P.1546-5}

Path loss yang dihasilkan oleh pemancar TV terestrial kota padang pada jarak $20 \mathrm{~km}$ yang dihitung menggunakan metoda ITU-R P.1546-5 dapat dilihat pada Gambar 6. Nilai path loss terbesar dihasilkan oleh pemancar indosiar sebesar $112.30 \mathrm{db}$ yang beroperasi pada frekuensi $695.25 \mathrm{MHz}$, sedangkan nilai path loss terkecil dihasilkan pemancar ANTV sebesar $112.27 \mathrm{db}$ yang beroperasi pada $663.25 \mathrm{MHz}$.

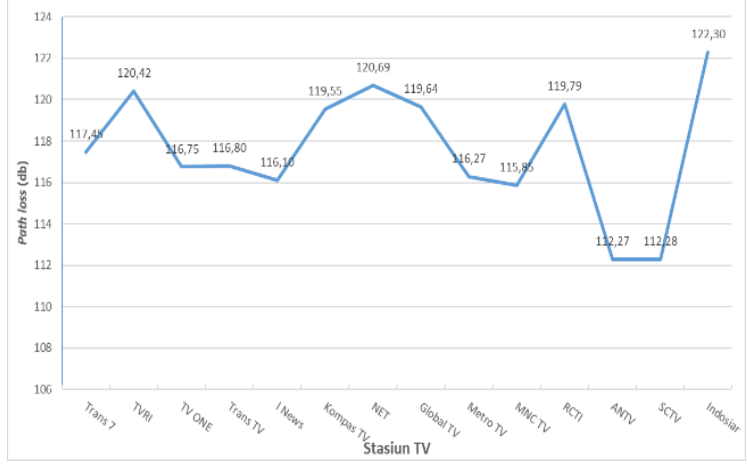

Gambar 6. Hasil Perhitungan Path Loss ITU-R P.1546-5 pada jarak $20 \mathrm{~km}$.
Dalam perhitungan path loss diggunakan metoda ITU.R P.1546-5, hasil yang didapatkan tidak linear dengan frekuensi operasi pemancar TV. Ketinggian antena pemancar berpengaruh terhadap nilai path loss yang dihasilkan. Selain itu perhitungan dilakukan dengan teknik interpolasi dan ekstrapolasi terhadap hasil pengukuran yang telah dilakukan. Pendekatan ini lebih akurat dibandingan dengan metode ITU-R P.525-2.

Berdasarkan hasil perhitungan path loss didapatkan kuat medan pemancar TV terestrial kota padang pada jarak $20 \mathrm{~km}$ seperti yang dapat dilihat pada Gambar 7. Kuat medan terbesar dihasilkan oleh pemanacar SCTV sebesar 69.47 $\mathrm{dbuV} / \mathrm{m}$ yang beroperasi pada frekuensi 679.25 $\mathrm{MHz}$.

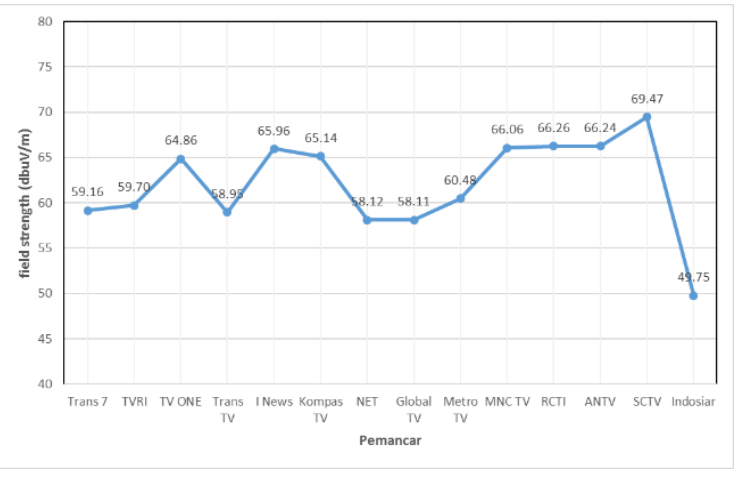

Gambar 7. Hasil Perhitungan Kuat medan Pemancar dengan Metode ITU-R P.1546-5 pada Jarak $20 \mathrm{~km}$

\subsection{Perbandingan Model ITU-R P.525-2 dengan ITU-R P.1546-5}

Perbedaan hasil perhitungan antara model ITU-R P.525-2 dengan ITU-R P.1546-5 disebabkan adanya perbedaan parameter yang terdapat dalam perhitungaan. Model ITU-R P.525-2 menggunakan parameter frekuensi dan jarak seangkan model ITU-R P.1546-5 menambahkan parameter ketinggian antenna pemancar dalam perhitungannya. Perbandingan hasil perhitungan kedua model dapat dilihat pada Tabel 3. Selisih antara kedua model terjadi pada pemancar Metro TV dengan selisih $1.62 \mathrm{db}$ sedangkan selisih terbesar pada pemancar TVRI sebesar $7.92 \mathrm{db}$. Sebagian besar nilai path loss yang dihasilkan metode ITU-R P.1546-5 lebih besar dibandigkan metode ITU-R P.525-2 kecuali untuk pemancar ANTV, SCTV dan Indosiar. 
Tabel 3. Perbandingan Hasil Perhitungan Path Loss metode ITU-R P.525-2 dengan ITU-R P.1546-5

\begin{tabular}{|c|c|c|c|c|}
\hline \multirow[b]{2}{*}{ No. } & \multirow[b]{2}{*}{ Pemancar } & \multicolumn{2}{|c|}{ Path Loss } & \multirow[b]{2}{*}{$\begin{array}{c}\text { Selisih } \\
\text { (db) }\end{array}$} \\
\hline & & $\begin{array}{c}\text { ITU-R } \\
\text { P.525-2 } \\
\text { (db) }\end{array}$ & $\begin{array}{c}\text { ITU-R } \\
\text { P.1546-5 } \\
\text { (db) }\end{array}$ & \\
\hline 1 & TRANS 7 & 112.23 & 117.45 & 5.22 \\
\hline 2 & TVRI & 112.51 & 120.42 & 7.92 \\
\hline 3 & TV ONE & 112.78 & 116.75 & 3.97 \\
\hline 4 & TRANS TV & 113.04 & 116.80 & 3.75 \\
\hline 5 & I NEWS & 113.30 & 116.10 & 2.81 \\
\hline 6 & KOMPAS TV & 113.55 & 119.55 & 6.00 \\
\hline 7 & NET & 113.79 & 120.69 & 6.90 \\
\hline 8 & GLOBAL TV & 114.02 & 119.64 & 5.62 \\
\hline 9 & MNC TV & 114.25 & 116.27 & 2.02 \\
\hline 10 & METRO TV & 114.22 & 115.85 & 1.62 \\
\hline 11 & RCTI & 114.69 & 119.79 & 5.10 \\
\hline 12 & ANTV & 114.90 & 112.27 & 2.64 \\
\hline 13 & SCTV & 115.11 & 112.28 & 2.83 \\
\hline 14 & INDOSIAR & 115.31 & 122.30 & 6.98 \\
\hline \multicolumn{4}{|c|}{ Rata - rata } & 4.53 \\
\hline
\end{tabular}

\section{KESIMPULAN}

Rekomendasi ITU-R P.525 dan rekomendasi ITU-R P.1546 memiliki hasil yang berbeda dalam perhitungan path loss spektrum frekuensi UHF untuk penyiaran TV terestrial Kota Padang. Rata - rata selisih perbedaan kedua metode tersebut sebesar $4.53 \mathrm{db}$. Perbedaan tersebut didapatkan karena kedua model memiliki pendekatan yang berbeda. Rekomendasi ITU-R P.1546 menggunakan parameter ketinggian antenna pemancar serta perhitungan interpolasi dan ekstrapolasi sedangkan ITU-R P.525 tidak menggunakan parameter ketinggian antenna pemancar serta menggunakan perhitungan dengan persamaan logaritmik.

\section{UCAPAN TERIMA KASIH}

Penelitian yang telah dilakukan dibiayai oleh dana dosen muda-universitas andalas sesuai dengan Surat Perjanjian Pelaksanaan Hibah Penelitian Nomor: 666/XIII/A/Unand/2016 Tanggal: 17 Febuari 2016.

\section{DAFTAR PUSTAKA}

[1] Bae, S-H., Cha, D-H, A New Approach for $1 \mathrm{~km}$ Urban Propagation Model of the Recommendation ITU-R P.1546, USNC-
URSI Radio Science Meeting (Joint with AP-S Symposium), 2014.

[2] Jang, J-S, Kang, M. S., Lee, K-h, A development of Prediction Program for Field Strength Using the ITU-R. P.1546 Recommendation with Geographic Information, International Conference on IT Convergence and Security (ICITCS), 2013.

[3] Kasampalis, S., Lazaridis, P. I., Zaharis, D., Bizopoulus, A., Zettas, S., Cosmas, J., Comaparison of Longley-Rice, ITU-R P.1546 and Hatta-Davidson Propagation Models for DVB_T Coverage Prediction, IEEE BMSB, 2014.

[4] M. Anedda, A. Anedda, M.Murroni, Coverage Optimization for DVB-T2 SFNs Using ITU-R P.1546 and ITU-R P.1812, IEEE International Symposium on Broadband Multimedia Systems and Broadcasting (BMSB), 2015.1

[5] Wei, W., Xia, N., Zhang, X., Song, K., Research on VHF/UHF Signal Localization Technique Based on ITU-R P.1546 Radio Wave Propagation Model, IEEE International Conference on Computer and Information Technology, 2014.

[6] Jimoh A.A., Surajunde-Bakinde N.T., Faruk, N., Ayeni, A.A., Obiyemi, O.O., Performance Analysis of Empirical Path Loss Models in VHF \& UHF BANDS, 6th International Conference on Information and Communiaction System, 2016.

[7] Olabisi, P. O., Aggregation of Power Losses in Radio Link Budgeting, IOSR Journal of Electronics and Communication Engineering, Vol. 9, Issue. 4, 2014.

[8] Munadi, R., Muetia, E. D., Fitriani, S., Evaluasi Kuat Medan Pemancar Radio FM pada Frekuensi 98.5-103.6 MHz di Kota Banda Aceh, Jurnal Rekayasa Elektrika, Vol. 11, No. 2, Oktober 2014.

[9] ITU-R Recommendation P.525-2, Calculation of Free-Space Attenuation, 1994.

[10] ITU-R Recommendation P.1546-5, Method for point-to-area predictionsfor terrestrial services in the frequenciy range $30 \mathrm{MHz}$ to $3000 \mathrm{MHz} . ", 2013$. 


\section{Biodata Penulis}

Hanalde Andre, Lahir di Rengat tahun 1986. Menyelesaikan Pendidikan S1 di Teknik Elektro Universitas Andalas pada tahun 2011, S2 Teknik Elektro double degree UNAND - ITB tahun 2013. Sekarang bekerja sebagai dosen di
Jurusan Teknik Elektro Fakultas Teknik Universitas Andalas.

Nofriadi, Lahir di Bukittinggi tahun 1969. Menyelesaikan S1 di STMIK Jayanusa dan S2 di UPI Padang. Sekarang bekerja di pengendalian spektrum frekuensi radio kota padang. 